Case Report

\title{
RETRO-AORTIC LEFT RENAL VEIN WITH DOUBLE LEFT RENAL ARTERY: A CASE REPORT
}

\author{
Vishal K. ${ }^{1}$, Vinay K.V. ${ }^{2}$, Remya $K_{.}^{3} \&$ Swathi ${ }^{4}$ \\ ${ }^{1}$ Associate Professor, ${ }^{2,4}$ Assistant Professors, ${ }^{3}$ Lecturer \\ Department of Anatomy, K.S. Hegde Medical Academy, Nitte University, Mangalore, Karnataka, INDIA \\ Correspondence : \\ Vishal Kumar \\ Associate Professor, Department of Anatomy, K.S. Hegde M edical Academy, Deralakatte, Mangalore - 575018 , \\ Karnataka, INDIA. M obile : +91 9845358754 E-mail : vishalkumarmd@gmail.com
}

\begin{abstract}
:
The kidneys are the excretory organs. The kidneys are supplied by right and left renal arteries at the level of second lumbar vertebrae. They are drained by right and left renal vein which runs anterior to renal arteries.

During routine dissection of an adult male cadaver in the department of Anatomy, we observed an unusual variation in the blood vessels supplying left kidney.

These variations are due to persistence of embryonic vessels.

Though variations in the renal vessels are common, proper knowledge of variations is essential not only to the anatomists but also for the clinicians and to perform surgical and radiological procedures more safely and efficiently.
\end{abstract}

Keywords: Kidney, Renal artery, Renal vein.

\section{Introduction:}

The renal arteries are large, paired arteries which takes origin from the lateral aspect of aorta at the level of upper part of $L 2$ second lumbar vertebra little below the origin of superior mesenteric artery. The left renal artery (LRA) is usually little higher than right one, it passes posterior to left renal vein (LRV) and then enters left kidney $(\mathrm{LK})^{1,2}$.

Both the renal veins are normally located anterior to renal arteries and the LRV which is longer compared to right renal vein opens into the inferior vena cava (IVC) which passes anterior to abdominal aorta ${ }^{1,2}$. About $30 \%$ of the population has accessory renal arteries ${ }^{3,4}$.

The Retro-aortic left renal vein (RALRV) is a rare and important variation related to the developmental process.

Access this article online Quick Response Code

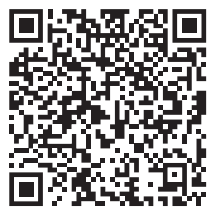
The knowledge about these variations is not only of academic interest but may also be of practical importance for radiologists $\&$ surgeons. In the present day, where hi-tech medical facilities are available there

is an increase in interventional radiological procedures, urological and vascular operations. In all these cases identification of variations in renal vascular pedicle is very useful for successful outcome.

\section{Case report:}

During the routine dissection of an adult male cadaver for undergraduate students at our college, we observed an unusual variation of double left renal arteries one below the other. The upper left renal artery (LRAU) was higher, wider than the lower left renal artery (LRAL). The calibre of the left renal arteries were smaller compared to the right renal artery (Figure 1). The LRV (Figure 1) crosses the midline by passing posterior to the abdominal aorta (RALRV) to enter IVC. On the right side, the renal artery \& vein were normal.

\section{Discussion:}

The venous variations are more common in our body compared to variations in the arteries. But it is not true in case of blood vessels of kidney, where arterial variations are quite common ${ }^{5}$. One or two accessory renal arteries are frequently found, more commonly on the left side. They usually arise from the aorta and may come off above or 


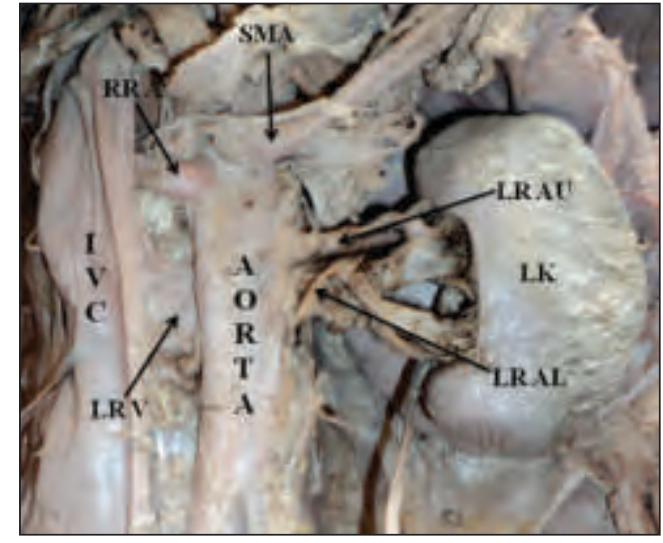

Fig 1 : Retroaortic left renal vein with double left renal artery. LK - Left Kidney, LRAU - Left renal artery upper, LR AL - Left renal artery lower, SM A - Superior mesentric artery, RRA - Right renal artery, LRV - Left renal vein, IVC-Inferior vena cava.

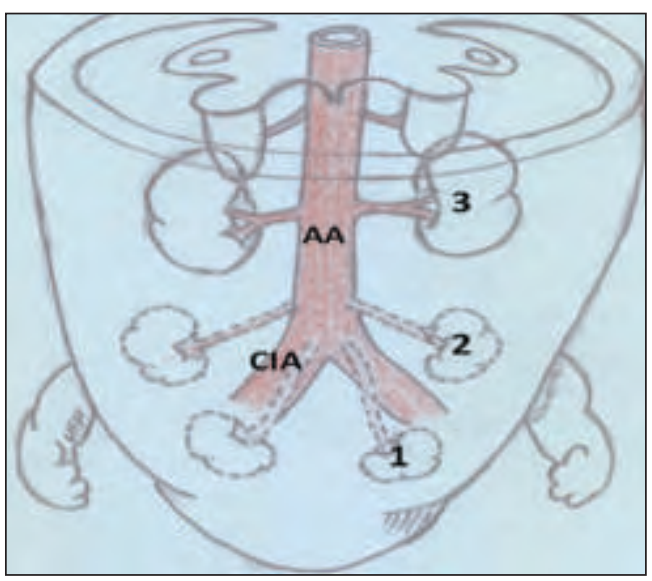

Fig 2 : Showing changing position Kidney and artery along with it. AA - Abdominal aorta. CIA - Common iliac artery. 1 - Kidney at $5^{\text {th }}$ week 2 - Kidney at $6^{\text {th }}$ week 3 - Kidney at $7^{\text {th }}$ week

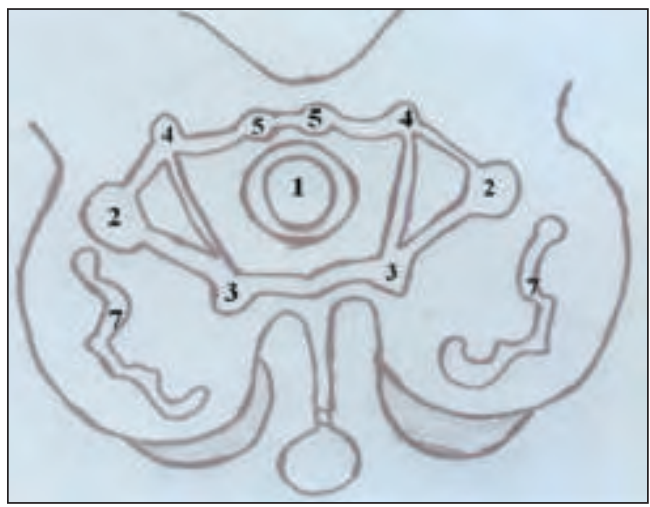

Fig2 : Showing renal collar in the embryonic period.

1 - Aorta 2 - Inferior cardinal vein 3- Subcardinal vein.

4-Supracardinal vein. 5 -Subcentral vein. 7 - M esonephros below the main artery, the former being the more common position. Instead of entering the kidney at the hilus, they usually pierce the upper or lower part of the organ ${ }^{3}$. Studies show that there is more than one renal artery in $15 \% \& 20 \%$ of cases on the right and left sides respectively ${ }^{6}$. Abnormalities of renal artery are due to changing position of kidney as a part of its development (Figure 2). The development of kidney begins in pelvic cavity and it then ascends to lumbar region. When they are in pelvic cavity they are supplied by internal iliac artery or common iliac artery. When they reach the lumbar region their arterial supply also shifts from common iliac to abdominal aorta. Thus, the knowledge of development of renal vasculature is essential in order to understand the possibilities of multiple anomalies and variations in renal arteries ${ }^{4,7,8}$.

The different origins of renal arteries and frequent variations are explained by the development of mesonephric arteries ${ }^{5}$. The renal artery may arise from the bifurcation of the aorta or from the common iliac, internal iliac, or inferior mesenteric artery. The branches of the renal artery may perforate the substance of the kidneys instead of entering from the hilus (so called accessory branches). The accessory renal arteries vary in size and are generally derived from the aorta?

The presence of accessory renal arteries can be explained embryologically as persistent lateral splanchnic branches of abdominal aorta during ascent of kidney from groin to loi ${ }^{10}$. Supernumerary renal arteries vary in number from two to four, rarely, five or six, arranged either unilaterally or bilaterally. A single renal artery on one side and multiple (two, three, or four) renal arteries on the other is not unusual $^{5}$. Jigna $\mathrm{K}$ Parmar found $16.66 \%$ accessory renal arteries on left side ${ }^{11}$ and Neelesh Kanaskar found that there were two additional renal arteries supplying the right kidney in addition to normal renal artery ${ }^{7}$. The reported incidence of additional renal arteries has a wide range between $8.7 \%$ and $75.7 \%{ }^{12}$.

Erol Sener reported a case where both the arterial trunks arise from aorta, which then bifurcated to form upper two 
renal arteries. The third renal artery directly arises from aorta in lower position on both sides ${ }^{9}$. Satheesha Nayak reports an extra inferior polar artery on left side ${ }^{13}$ The radiological study conducted on 855 patients reports that about $12 \%$ of the patients having double renal arteries on the left side ${ }^{5,14}$.

The RALRV anomaly is a relatively uncommon condition ${ }^{5}$. The cardinal veins form the main channel of venous drainage in initial stage of developing embryo During the $5^{\text {th }}$ to $7^{\text {th }}$ week, paired longitudinal channels, the subcardinal, the supracardinal veins appear by the sides of the posterior cardinal veins ${ }^{15,16,17}$. Later, the sub-central and azygos venous lines will be formed ${ }^{17}$. These veins will form anastomotic channel around dorsal aorta called renal collar ${ }^{3,15,16,17}$. Due to the persistence of dorsal limb of circumaortic collar (Figure 3) and disappearance of preaortic segment of renal collar will lead to RALRV ${ }^{4,5,10 \text {, }}$

The precaval renal artery is a rare variation, the reported prevalence being $0.8 \%{ }^{18}$. Satyapal et al, reported $0.5 \%$ of RALRV in 1008 case $^{19}$. Praveen kumar $M$ also found a case

\section{Refrerences :}

1. Hollinshead W. H. Anatomy for surgeons, $2^{\text {nd }}$ edn. 1961; pp.542-546, Harper Row Publishers, New York.

2. G.J.Romanes. Cunningham's manual of Practical Anatomy, $15^{\text {th }}$ edn Vol.2, 2007; pp.175-176, Oxford M edical Publication, London.

3. Stardring S. Gray's Anatomy, $40^{\text {th }}$ edn. 2008; pp 1231-33, Churchill Livingstone Elsevier Limited, London.

4. Praveen KM, Suseelamma D, Saritha S and Lingaswamy V. Multiple Renal Vascular Variations. Open Access Scientific Reports. Volume 1, Issue 6, 2012; pp.1-2.

5. Parimala NBS, Ratnaprabha $\mathrm{CH}$, Prabhakara Rao M. Triple renal arteries and retro aortic left renal vein-A case report. National journal of clinical Anatomy. 2013; Vol 2(1) pp.38-40.

6. Decker CAG. Lee Mc Gregor's synopsis of surgical anatomy. $12^{\text {th }}$ edn. 1986; pp.295-97, Akshar Pratiroop Pvt Ltd, Bombay.

7. Neelesh K, Vaishali P, Jyoti K, Sapna S. Double Accessory Right Renal Arteries. Journal of Dental and M edical Sciences. Volume 1, Issue 5, Sep-Oct. 2012; pp.17-20.

8. Nayak BS. M ultiple variations of the right renal Vessels. Singapore med journal. 2008; 49(6), pp.153-155.

9. Erol S, Alper H.U, Kanat O, Levent C, M ustafa E. Bilateral triple renal arteries. Journal of Ankara University Faculty of M edicine. 2005; 58(1). pp.18-19.

10. Subhra M, Prabir M, Ranjan B. Bilateral Accessory Renal Arteries, Additional Right Renal Vein and Retroaortic Left Renal Vein- A Case Report. International Journal of Health Sciences \& Research. Vol. 3; Issue 2; February 2013; pp.88-89.

11. Jigna KP, Subhash G, Sanjay V, Dharti K, Shaileshkumar N, Wani IN, et al. on RALRV out of 30 specimens studied ${ }^{4}$. The CT study in 433 cases reveals 1.8\% RALRV by Reed et al., and Trigaux et al., conducted CT study of 1014 cases and found 3.7\% of RALRV cases $^{5}$.

Recent reports have associated renal vascular anomaly with galactosemia ${ }^{7,20}$. But here we do not have any medical records to comment. It is important to be aware that accessory renal arteries are end arteries; therefore if an accessory artery is damaged, the part of kidney supplied by it is likely to become ischaemic ${ }^{4,8}$.

\section{Conclusion:}

These kind of multiple variations may remain silent clinically and unnoticed until discovered during operation, radiological investigation or during an autopsy. To the transplant surgeon and any surgery involving retroperitoneal region morphology of the renal vessels acquires a special significance, since variations and anomalies may greatly influence the technical feasibility of the operation. So the knowledge about these kinds of variations is very usefull.

IJBAR. 2012; 03(11) pp. 815-817.

12. Necdet K, Bülent Y, Cenk K, Yalçýn K, Hasan O. Accessory renal arteries and an anomalous testicular artery of high origin. Gülhane Týp Dergisi 2005; 47: pp. 141-143.

13. Satheesh N B. Presence of accessory renal artery and kinking of aorta due to abnormal origin of renal arteries. The Internet Journal of Biological Anthropology. 2008; 1(2).DOI:10.5580/115c, 20/06/2013.

14. Ugur O, Levent O, Fahri T, Osman K, Zafer K, Nihal K. Renal artery origins and variations: angiographic evaluation of 855 consecutive patients. Diagn Interv Radiol. 2006; 12: pp.183-186.

15. Moore K L and Persaud TVN. The Developing Human- Clinically oriented embryology. $6^{\text {th }}$ edn, 1998; pp. 310-313. Saunders, Philadelphia.

16. Sadler T.W. Langman's Medical Embryology.11 $11^{\text {th }}$ edn. 2010; pp.235242. Lippincott Williams \& Wilkins, Philadelphia.

17. Datta A.K. Essentials of human Embryology. $5^{\text {th }}$ edn, 2010; pp. 201219. Current Books International, Kolkatta.

18. Ambica W and Sandeep S. Double Precaval Right Renal Arteries - Its Clinical Implications. Int J M ed Health Sci. October 2012; Vol-1;Issue-4. pp.76-79.

19. Satyapal KS, Kalideen JM , Haffejee AA, Singh B, Robbs N. Left renal vein variations. Surg RadiolAnat. 1999; 21: pp. 77-81.

20. Khin PPH, Srijith D, Isra MS, Azian AL, Norzana AG, Farhah HS, et al. Accesory renal vessels at upper and lower poles of kidney. Bratisl Lek Listy. 2010;111(5) pp. 308-310. 